\title{
DETERMINATION OF THIAMINE HCL (VITAMIN B1) AND PYRIDOXINE HCL (VITAMIN B6) CONTENT IN TABLET BY FTIR
}

\author{
ILMA NUGRAHANI, CITRA KARTINI \\ Bandung Institute of Technology Indonesia \\ Email: ilma_nugrahani@fa.itb.ac.id
}

Received: 11 Jul 2016 Revised and Accepted: 23 Aug 2016

\section{ABSTRACT}

Objective: The combination of thiamine hydrochloride (vitamin B1) with pyridoxine hydrochloride (vitamin B6) has been efficacious to help the metabolism of carbohydrates and amino acids. FTIR (Fourier transform infrared) is a technique widely used in compound identification and determination of functional groups but rarely used for the quantitative purposes. This study aims to obtain a analysis determination method of this vitamin combination simultaneously in tablet dosage form using FTIR.

Methods: Amount of vitamin B1 and B6 standard were mixed with KBr crystal in a series of concentration (\% w/w) in kalium bromide (kbr) crystal, then measured with FTIR. These spectrums yielded were transformed into an absorbance afterward changed to its derivative. The finest spectrum, which showed the best specificity and linearity, was selected and its area under the curve was calculated. The other validation parameters: accuracy, precision, detection limit, quantitation limit, and ranges, next were tested and determined. The validated method than was used to analyze the levels of vitamin B1 and B6 simultaneously in the tablets.

Results: Vitamin B1 and B6 have the linear concentration range from 0.5 to $3.00 \% \mathrm{w} / \mathrm{w}$. The regression equation for vitamin $\mathrm{B} 1$ is $\mathrm{y}=0.0608 \mathrm{x}-$ 0.0176 with $r=0.9997$ and $\mathrm{Vx} 0=1.5047 \%$, for vitamin $\mathrm{B} 6: \mathrm{y}=0.0977 \mathrm{x}+0.0079 \mathrm{r}=0.9995$ and Vx0 $=1.7832 \%$. Recovery results of vitamin $\mathrm{B} 1$ : 98.98 to $100.93 \%$, while B6: 99.06 to $100.43 \%$. Intra-day and inter-day precision for vitamin B1: $1.73 ; 1.62 ; 1.48$, and $0.58 \%$, meanwhile for vitamin B6: $1.29 ; 1.60 ; 1.78$, and $1.39 \%$. The limits of detection and quantitation for vitamin B12 was 0.079 and $0.263 \% \mathrm{w} / \mathrm{w}$ respectively, and for vitamin B6, was: 0.093 and $0.311 \% \mathrm{w} / \mathrm{w}$. The tablets from the market were tested showed the results that meet with compendia requirements.

Conclusion: FTIR can be used for the determination of levels of vitamin B1 and B6 simultaneously in tablet dosage form and have met the validation requirements.

Keywords: Validation of method, FTIR, Derivative spectra, Thiamine hydrochloride, Pyridoxine hydrochloride

(C) 2016 The Authors. Published by Innovare Academic Sciences Pvt Ltd. This is an open access article under the CC BY license (http://creativecommons.org/licenses/by/4. 0/) DOI: http://dx.doi.org/10.22159/ijpps.2016v8i10.14026

\section{INTRODUCTION}

A method for quantitative analysis of active compound in pharmaceutical preparations is growing rapidly. The development of methods has goals to provide a process that is simple, quick, and easy, and has to fulfill the acceptance criteria of validation. According to the Indonesian Pharmacopoeia $\mathrm{V}$, validation of analytical methods is a process established through laboratory studies that the performance characteristics of these methods meet the requirements according to their intended use [1]. The parameters in the validation of methods include specificity, linearity, accuracy, precision, detection limit, quantitation limit, and range [2-4].

Thiamine (vitamin B1) can help the process of metabolism, especially of carbohydrates, meanwhile pyridoxine (vitamin B6) helps in the regulation of amino acids and hormones in the body [5, 6]. Multivitamin products from the market mostly contain a combination of vitamins B1 and B6, in Indonesia can be found both in generic either branded names $[7,8]$.

A generic drug is identical or bioequivalent to a brand-name drug in dosage form, safety, strength, route of administration, quality, performance characteristics and intended use [9]. In other words, generic drugs mean a group of dosage forms, which produced and marketed in similar actions with same names. Meanwhile, the other has their own brand name, which often chosen by the manufacturer to be memorable for trading. The robust growth of the generic drug industry has been based on the premise that it provides the same efficacy and safety as branded drugs, but at a substantially reduced cost [10].

Several analytical methods have been used for the determination of vitamins B1 and B6 either alone or in combination in the dosage forms. The method of analysis commonly used is high performed liquid chromatography (HPLC). This method is used as a standard method within compendia for the determination of drug substances in a combination dosage form $[1,11,12]$. Indonesian Pharmacopoeia $\mathrm{V}$ states that the assay of both active compounds in the tablet al. so must be done by HPLC [1]. Some publications have reported the HPLC with some detector using to analyze the multivitamin B, i.e. uv, dad (diode array), and FLD (fluorescence detector) [13, 14].

On the other hand, FTIR has not been commonly used for quantitative analysis purpose. This technique is still widely used for identification and determination of functional groups in the qualitative analysis $[15,16]$. However, in some publications, FTIR method has been developed and used for quantitative analysis of pharmaceutical preparations [17-20]. This method offers some advantages, such as a simpler preparation of the sample and easier technique, as well as needed lesser organic solvents.

The technique which developed, used the principle of measuring the transmission or absorbance of the analytes in a mixture of halide salts as a function of frequency or wave number. The absorption of infrared radiation causes molecular excitation of lower vibration energy levels to a higher level of vibration, which was followed by changes in the dipole moment of the bonds. FTIR has replaced the dispersive instruments in a variety of applications because it is faster and more sensitive. Moreover, unlike the previous instrument which is monochromatic, all frequencies are measured simultaneously in FTIR spectroscopy. Vibration spectroscopy measurements are mostly done in the middle ir wavelength range, the $4000-400 \mathrm{~cm}^{-1}[15,16]$.

Vitamin B1 is soluble in water and glycerin, sparingly in ethanol, insoluble in ether and in toluene. The specific functional group of 
thiamine is an amine primer $[1,5,15,16]$. Similar with vitamin B1, B6 is freely soluble in water, sparingly in ethanol, and insoluble in ether. This compound was expected to have a specific infra-red spectrum, which is typical in the presence of strong $\mathrm{C}-\mathrm{O}$ vibration of the phenolic groups $[1,6,10,11]$, then can be used for analysis. This study aims at the development and validation of FTIR method for quantitative analysis of vitamins B1 and B6 simultaneously in the tablet dosage form.

\section{Instruments}

The tools used in this study were the pestle (China), mortar (China), electronic milligram scale (Mettler AE 200, Switzerland) FTIR (Jasco-4200 type A, Japan), FTIR pellet presser (Jasco mini press MP1, Japan), kbr oven (Memmert, Germany).

\section{Materials}

The materials used in this study included standard for vitamins B1 and B6 (Merck, Germany), kbr crystal (spectral grade), acetone (Merck, Germany) lactose (Brataco, Indonesia), PEG 6000 (Brataco, Indonesia), aerosil (Brataco, Indonesia), parchment paper, and the samples of generic and brand-name multivitamin tablet B (from 2 industries in Indonesia).

\section{Procedures}

\section{FTIR spectra measurement of vitamin B1 and B6}

A series of concentration respectively vitamins B1 and B6 standard in $\mathrm{KBr}$ crystals from 0.50 to $3.00 \% \mathrm{w} / \mathrm{w}$ were prepared. These mixtures were weighed as much as $10 \mathrm{mg}$, then compressed in a compactor tool with a pressure of 20 psi. Plates yielded then were measured using a Jasco FTIR-4200 type A at wave number 4000 to $400 \mathrm{~cm}^{-1}$ and performed three times measurements.

\section{Derivatization of vitamins B1 and B6 spectrums}

Spectrums that have been found next were converted into absorbance peaks. After that, the absorbance peaks were transformed into their derivation that more clearly apparent. These were then calculated the area under the peaks at some wave number range.

\section{Determination the specific spectra of vitamins B1 and B6}

The finest spectra were observed. Afterwards it was derivated, then the area under the curve (AUC) was calculated. The wave numbers of the amine primer (1646.91 to $1662.34 \mathrm{~cm}^{-1}$ ) for vitamin B1, meanwhile CO wave numbers (from 1280.5 to $1315.21 \mathrm{~cm}^{-1}$ ) for vitamin B6 and some spectrum in several other wave numbers also determined. It was furthermore plotted the concentrations in kbr of vitamins $\mathrm{B} 1$ and $\mathrm{B} 6(\% \mathrm{w} / \mathrm{w})$ towards the area under the curve. Finally, the linearities of calibration curves were compared to fix the most linear regression curve.

\section{Correction for the matrix spectra}

A general formulation (contained excipients and the drugs) for multivitamin tablets was prepared, which contained lactose, gelatin, PEG 6000 and aerosil. Further, a formula containing just excipients without active substance, a matrix with vitamin B1, a mixture of the matrix with vitamin B6, and a combination formula contained both of drugs were analyzed by FTIR. All the spectrums yielded then were overlaid.

\section{Validation methods}

Validation parameters of vitamins B1 and B6 assay which were tested were included specificity, linearity, accuracy, precision, range, limit of detection (lod) and the limit of quantitation (loq) [2-4].

\section{Specificity tests}

The derivative spectrum of the matrix alone and mixtures with active substances were overlaid. A selected range of the specific wave number for each of vitamin B1 and vitamin B6 with the most excellent linearity was observed and fixed.

\section{Linearity tests}

A series of concentration of vitamins $\mathrm{B} 1$ and $\mathrm{B} 6$ respectively: 0.50; $1.00 ; 1.50 ; 2.00 ; 2.50 ; 3.00 \% \mathrm{w} / \mathrm{w}$ in kbr was prepared. Next, the
FTIR measurements were conducted. The plotting between the area under the curve was composed as a regression curve, which then determined its linearity. Acceptance criterion for linearity is $r$ (correlation coefficient) $\geq 0.999$, meanwhile the coefficient of variance and regression function was (VXO) $\leq 2.0 \%[2-4]$.

\section{Precision tests}

A tablet was crushed as a blank for the standard addition. It was then added to make a combination of active substances vitamins B1 and B6 with the respective amount of $100 \%$ (vitamin B1 equivalent of $100 \mathrm{mg}$ and $\mathrm{B} 6$ equivalent to $200 \mathrm{mg}$ ). Afterward, each was sampled as much as $6 \mathrm{mg}$ and mixed with $\mathrm{KBr}$ to be $100 \mathrm{mg}$. The precision measurement was done by repeating six times in one day of raw vitamin $\mathrm{B} 1$ concentration equivalent to $1 \% \mathrm{w} / \mathrm{w}$ and a vitamin B6 equivalents to $2 \% \mathrm{w} / \mathrm{w}$. Measurements were also performed on three different days. The acceptance criteria of precision is a relative deviation standard $(\mathrm{rds})<2 \%[2-4]$.

\section{Range tests}

The range of concentration used in linearity, accuracy, and precision, was determined from the observation and equation yielded.

\section{Limit detection and the limit of quantification}

The limits of detection and quantitation limits were estimated from the standard curve. It was by the following equation:

$$
\begin{gathered}
\text { Limit of detection (lod) }=\frac{3 S y}{x} / b \ldots \text { (1) } \\
\text { Limit of quantification }(\operatorname{loq})=\frac{10 S y}{x} / b \text { with } \frac{\text { Sy }}{x}=\left[\left(\sum\left(y_{-} i-\hat{y}_{-} i\right)^{\wedge} 2\right) /(n-\right. \\
2)]^{\wedge}(1 / 2) . .(2)[2-4] .
\end{gathered}
$$

Determination content of the active compounds in the multivitamin tablets

In the next step, the content of two brand name tablets consisted of these vitamins were analyzed. Firstly, a total of 20 tablets of each product weighed afterward computed the average. All the crushed tablet sampled mixed homogeneous, with vitamin B1 and B6 respectively, with each concentration was $1 \% \mathrm{w} / \mathrm{w}$ and $2 \% \mathrm{w} / \mathrm{w}$. This mixture next dispersed in $\mathrm{KBr}$ until reached as much as $100 \mathrm{mg}$. The measurement and assay were performed using the developed FTIR method [1].

\section{RESULTS AND DISCUSSION}

\section{FTIR spectra of vitamins B1 and B6}

Development of the assay method of vitamins B1 and B6 in their combination tablet were begun with the observation of their spectrum. A series of vitamin B1 concentration of 0.50 to $3.00 \%$ (in the mixture with B6 2\%) was measured using the FTIR. The spectrums produced, then were transformed into an absorbance function. The conversion into a form of absorbance must be done, due to the absorbance value will be more linear proportional to the concentration. Afterward, to increase the sensitivity, the absorption spectra was changed into its second derivative, then measured its area under the curve. Here is an overlaid of vitamin B1 spectral in a series concentration, which was converted into the absorbance transmission forms (fig. 1).

Furthermore, the derivatization of the spectrum that has been converted into the form of an absorbance was conducted. Derivatization was done by performing baseline correction spectrum and converted it into the first derivative form. Next, the area under the curve of the spectra was calculated with axis $=0$ at the particular wave number range [13]. On the spectrum of derivatives formed by the standard of vitamin B1, it will have some range of wave numbers were on spacious significant than others. Two strong spectra areas signed as a and b in fig. 2 were selected. These are $1646.91-1662.34$ and $1662.34-1700.91 \mathrm{~cm}^{-1}$, which were next tested their linearity.

Table 1 listed the area under the curve data of two candidates spectra laid at 1646.91-1662.34 and $1662.34-1700.91 \mathrm{~cm}^{-1}$. These areas showed the highest linear correlation ( $\mathrm{r}$ value) towards the concentrations. The result shows that (b) has the finest curve. 


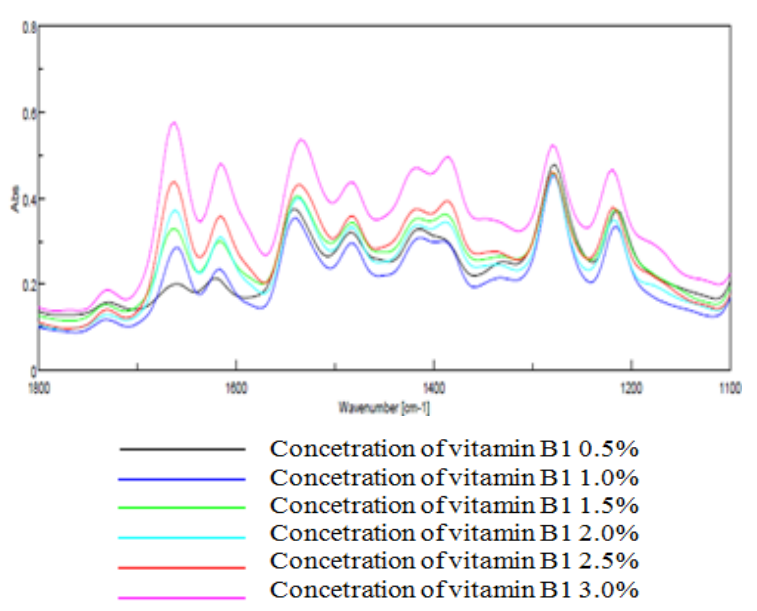

Fig. 1: Spectrum of vitamin B1 in absorbance function at wave number $1800-1100 \mathrm{~cm}^{-1}$
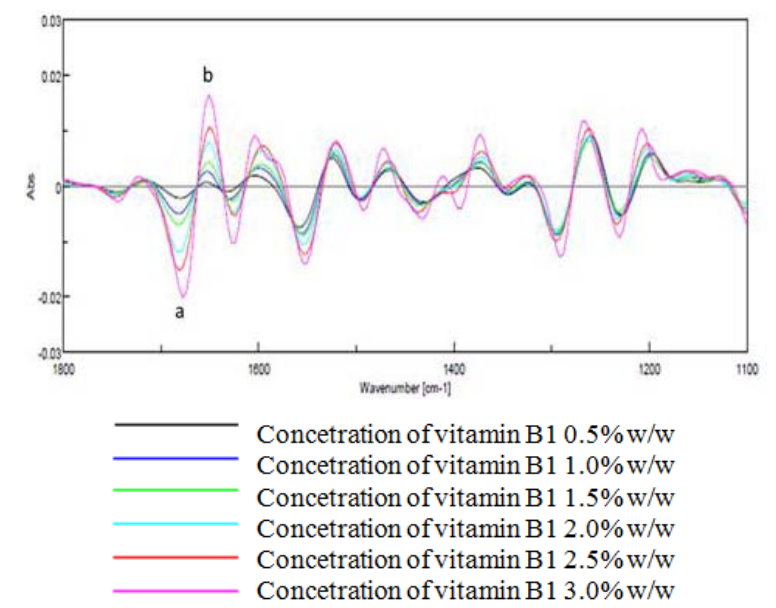

Fig. 2: The overlaid of a series concentration of vitamin B1 spectra derivativeswith noted at wave numbers: (a) 1662.34$1700.91 \mathrm{~cm}^{-1}$ and (b) $1646.91-1662.34 \mathrm{~cm}^{-1}$

Table 1: Concentration of standard vitamin B1 and its absorbance derivate

\begin{tabular}{lll}
\hline $\begin{array}{l}\text { Vitamin B1 } \\
\text { concentration }(\%\end{array}$ & \multicolumn{2}{c}{$\begin{array}{l}\text { Auc of derivate absorbance curve at } \\
\text { the wave number }\left(\mathbf{c m}^{-1}\right)\end{array}$} \\
\cline { 2 - 3 } $\mathbf{w}$ w) & $\mathbf{1 6 4 6 . 9 1 - 1 6 6 2 . 3 4}$ & $\mathbf{1 6 6 2 . 3 4 - 1 7 0 0 . 9 1}$ \\
\hline 0.5 & 0.0136 & 0.0573 \\
1.0 & 0.0442 & 0.1270 \\
1.5 & 0.0722 & 0.1882 \\
2.0 & 0.1020 & 0.2452 \\
2.5 & 0.1343 & 0.3346 \\
3.0 & 0.1664 & 0.4132 \\
Linearity (r) & 0.9997 & 0.9972 \\
\hline
\end{tabular}

From some of the wave numbers, a range of wave number 1646.91$1662.34 \mathrm{~cm}^{-1}$ was selected. That is the group $\mathrm{N}-\mathrm{H}$ spectra because it has the highest linearity, i.e. 0.9997. After correction of the matrix formulation excipients that were tailored, which indicated a number range that only owned by vitamin B1 and not owned by vitamin B6 nor the matrix. N-H group primer vibration will show a peak at $1650-1590 \mathrm{~cm}^{-1}[15,16]$. Thereby the spectra of $\mathrm{N}-\mathrm{H}$ groups has been used as the basis for a quantitative calculation of the levels of vitamin B1 tablet (fig. 3).

In the following step, a series of vitamin B6 concentration of 0.50 to $3.00 \% \mathrm{w} / \mathrm{w}$ (mixtures with B1 1\% w/w) was prepared. It was dispersed in $\mathrm{KBr}$ plate, next was measured using the FTIR. The spectrums produced were transformed into an absorbance then were derived. First scanning was done in $1800-1100 \mathrm{~cm}^{-1}$, which afterward focused to the strong curves. These were laid at 1531.2 $1569.77 \mathrm{~cm}^{-1}$ and $1280.5-1315.21 \mathrm{~cm}^{-1}$. The results are shown in fig. 4 and 5 respectively.

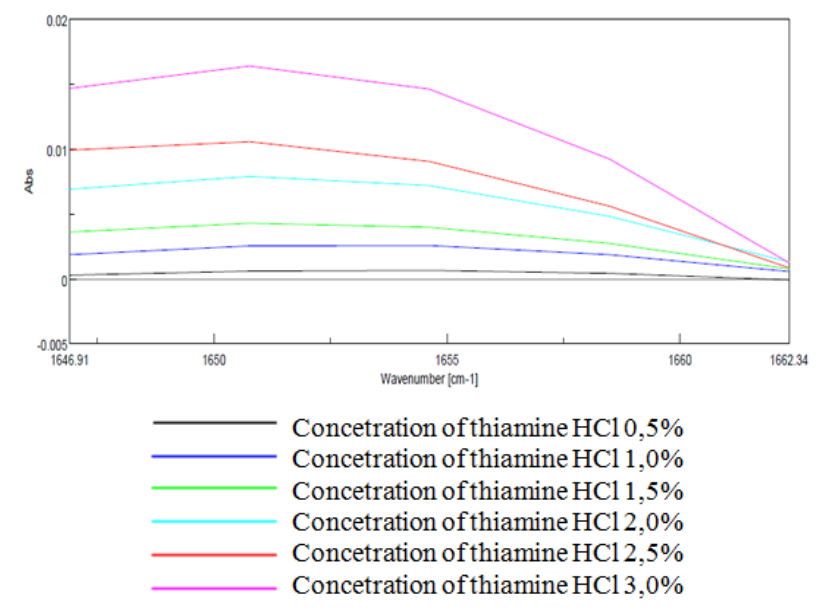

Fig. 3: Vitamin B1 spectra derivatives at wave numbers 1646.91-1662.34 $\mathrm{cm}^{-1}$

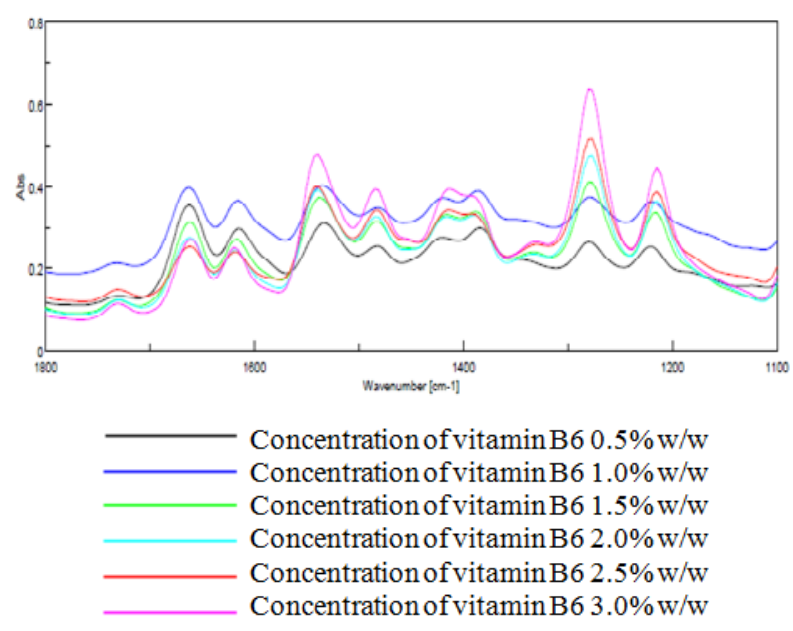

Fig. 4: The spectra derivatives of vitamin $B 6$ in the wave numbers 1800-1100 cm-1

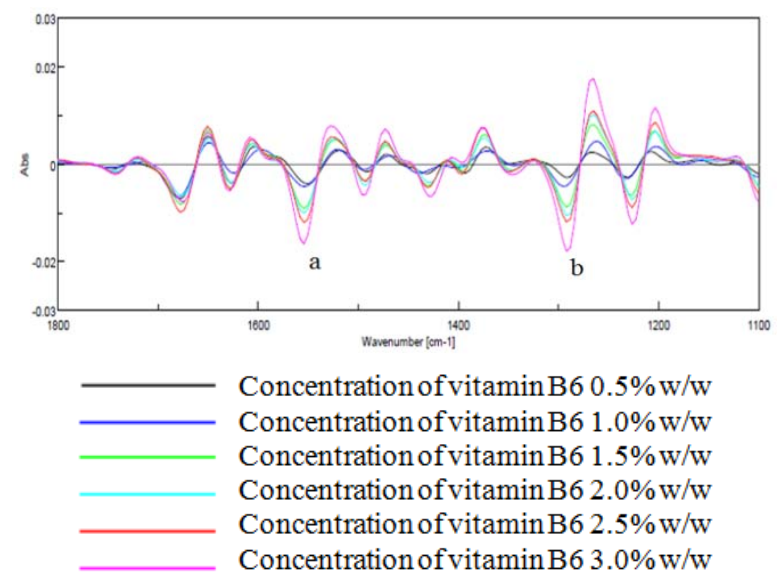

Fig. 5: The spectra derivatives of vitamin $B 6$ in the wave numbers, (a) 1531.2-1569.77 $\mathrm{cm}^{-1}$ and (b) $1280.5-1315.21 \mathrm{~cm}^{-1}$ 
The range of a wave number selected for B6 was 1280.5-1315.21 $\mathrm{cm}^{-1}$, which owned by the group C-0 $[15,16]$. This spectrum area had the highest linearity correlation between its area under the curve (AUC) with the concentration, i.e. $r=0.9995$. Stretching vibration-C-O of the phenolic group will produce a strong band in the range of wave numbers of about $1200 \mathrm{~cm}^{-1}[15,16]$. Based on the data, this spectrum was selected to be used as the basis for a quantitative calculation of the levels of vitamin B6 in the tablet. The spectrum derivates at this area are shown in fig. 6 .

The AUC of the derivatives of absorbance spectrums of two wave number areas are listed in table 1 . From these data, the regression curves were composed and compared. The most linear curve represented the best area which must be chosen.

Table 2: Concentration of standard vitamin $\mathrm{B} 6$ and its absorbance derivate

\begin{tabular}{llr}
\hline Concentration of vitamin B6 in $\mathrm{KBr}(\% \mathbf{w} / \mathbf{w})$ & \multicolumn{2}{l}{ AUC of absorbance derivate curve at the wavelength of (cm-1) } \\
\cline { 2 - 3 } & $\mathbf{1 2 8 0 . 5 - 1 3 1 5 . 2 1}$ & 0.1069 \\
0.5 & 0.0540 & 0.1325 \\
1.0 & 0.1064 & 0.1835 \\
1.5 & 0.1549 & 0.2185 \\
2.0 & 0.2068 & 0.2392 \\
2.5 & 0.2536 & 0.3000 \\
3.0 & 0.2972 & 0.9921 \\
Linearity (r) & 0.9995 & \\
\hline
\end{tabular}

Auc: area under the curve

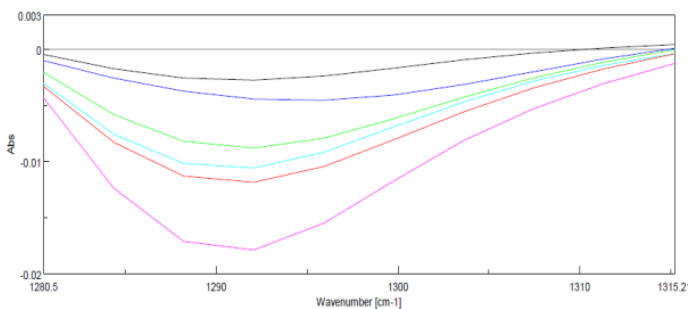

Concentration of vitamin $\mathrm{B} 60.5 \% \mathrm{w} / \mathrm{w}$ Concentration of vitamin $\mathrm{B} 61.0 \% \mathrm{w} / \mathrm{w}$ Concentration of vitamin $\mathrm{B} 61.5 \% \mathrm{w} / \mathrm{w}$ Concentration of vitamin $\mathrm{B} 62.0 \% \mathrm{w} / \mathrm{w}$ Concentration of vitamin $\mathrm{B} 62.5 \% \mathrm{w} / \mathrm{w}$ Concentration of vitamin $\mathrm{B} 63.0 \% \mathrm{w} / \mathrm{w}$

Fig. 6: The spectrum derivatives of vitamin $B 6$ at wave number $1280.5-1315.21 \mathrm{~cm}^{-1}$

\section{Specificity}

Specificity is the ability to accurately and precisely measure an analyte in the presence of other components, which may be in the sample matrix. This method was done by comparing the spectral derivative of vitamin B1, vitamin B6, and tablet formulation based on a general formula with the derivative spectra matrix. The overlaid of all derivated spectrums are shown in fig. 7.

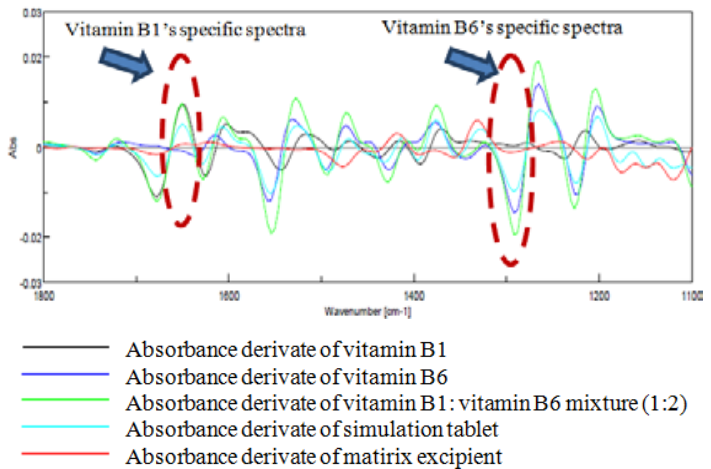

Fig. 7: The derivate spectrum of absorbances of vitamin B1, vitamin B6, a combination of vitamin B1 and B6 (1:2), tablet simulation, and the matrix

The specific spectra were selected, which should be owned by vitamin B1 and B6 only, but not by the matrix. Then, it can be used as the basis to measure the levels of vitamin B1 and B6 in multivitamin tablet samples.
Calibration curves and linearity

\section{Linearity}

Linearity was observed from the standard curve of both active compounds respectively. The data used were from the series concentrations of $0.50 ; 1.00 ; 1.50 ; 2.00 ; 2.50$; and $3.00 \% \mathrm{w} / \mathrm{w}$. These concentrations then were plotted against the area under the curve of derivative absorbance curves. The linearity of the curve is expressed by the correlation coefficient (r) of the linear equation. Data are shown in table 1 and 2 with the regression curves supported are shown in fig. 8 and 9 .

The regression curve was yielded as shown in fig. 8, composed based on the data listed in table 1.

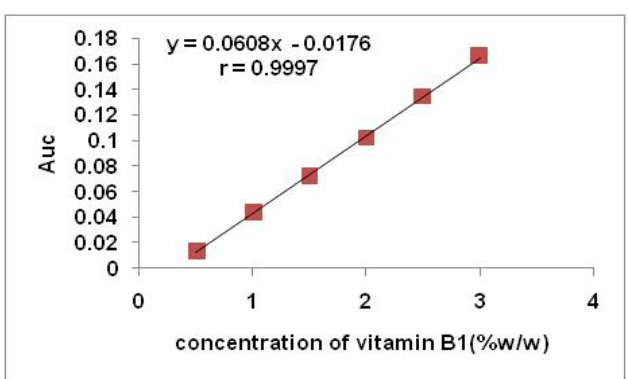

Fig. 7: Calibration curve of standard vitamin B1 against the area under curve of absorbance derivate

Linear regression equation of vitamin B1 was resulted from its calibration curve: $\mathrm{y}=0.0608 \mathrm{x}-0.0176$ with a correlation coefficient $(r)=0.9997$, as shown in fig. 8. The Vx0 value was $1.5047 \%$ as explained in table 2. Meanwhile, the experiment on vitamin B6 produced data as listed in table 2 , with the regression curve yielded is shown in fig. 9 below:

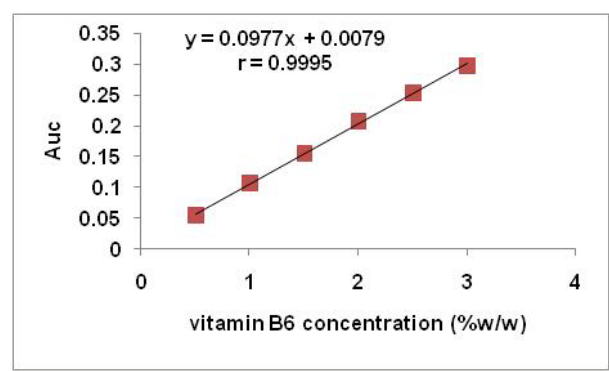

Fig. 8: Vitamin B6 calibration curve of concentration versus AUC of its absorbance derivate 
Meanwhile, vitamin B6 has the linear regression equation: $\mathrm{y}=$ $0.0977 \mathrm{x}+0.0079$ with correlation coefficients $(\mathrm{r})=0.9995$ and $\mathrm{Vx} 0$ value $=1.7832 \%$. Based on these data, it can be stated that the method used has been qualified of acceptance linearity.

\section{Validation test}

\section{Accuracy}

In this experiment, the standard addition method was used Accuracy is expressed as a percent recovery from the added analytes [2-4]. One tablet was crushed to be used as blank, then was added with a combination of vitamins B1 and B6 (1: 2). The mixtures were prepared with active substance content of 80,100 , and $120 \%$. These three mixtures then were each weighed as $6 \mathrm{mg}$, ground with $\mathrm{kbr}$ until the mass of $100 \mathrm{mg}$, next compress to be a plat. The results of accuracy test of standard substances are shown in table 3 and 4 for vitamin B1 and B6 respectively.

\section{Precision tests}

Precision declared level distribution measurements obtained from multiple samplings homogeneous under the recommended conditions [2-4]. In stating the precise value for the relative standard deviation is used. Precision tests included intra-and interday explained below

\section{Intra-day precision}

Precision intra-day stated precision under conditions, which at the same time the interval was narrow [3]. In this study, each sample was tested by 6 (six) time measurements, which were carried out using the addition method of the vitamins B1 and B6 combination. The concentrations of B1 and B6 were 100 and $200 \mathrm{mg}$ which equivalent of $100 \%$ in one day. The results of this experiment for were shown in table 5 and 6 as follows

Table 3: Accuration data of vitamin B1 standard

\begin{tabular}{|c|c|c|c|c|}
\hline Concentration & Auc (1646.91-1662.34 $\left.\mathrm{cm}^{-1}\right)$ & Average of AUC & Theoretical AUC & Percent of recovery (\%) \\
\hline $80 \%$ & $\begin{array}{l}0.0296 \\
0.0307 \\
0.0318\end{array}$ & $0.0307 \pm 0.0011$ & 0.0310 & 98.98 \\
\hline $100 \%$ & $\begin{array}{l}0.0437 \\
0.0442 \\
0.0429\end{array}$ & $0.0436 \pm 0.0007$ & 0.0432 & 100.93 \\
\hline $120 \%$ & $\begin{array}{l}0.0564 \\
0.0562 \\
0.0520\end{array}$ & $0.0549 \pm 0.0025$ & 0.0553 & 99.22 \\
\hline
\end{tabular}

Table 4: Accuration data of vitamin B6 standard

\begin{tabular}{llll}
\hline Concentration & Auc (1280.5-1315.21 $\left.\mathbf{~ c m}^{-1}\right)$ & Average of auc & Theoretical AUC \\
\hline $80 \%$ & 0.1764 & $0.1649 \pm 0.0110$ & 0.1642 \\
& 0.1545 & & \\
& 0.1637 & $0.2014 \pm 0.0101$ & 0.2033 \\
$100 \%$ & 0.2058 & & \\
& 0.1899 & & \\
$120 \%$ & 0.2085 & $0.2427 \pm 0.0115$ & 0.2424 \\
& 0.2559 & & \\
\hline
\end{tabular}

Auc: area under the curve

Table 5: Precision intraday test data of vitamin B1 standard

\begin{tabular}{|c|c|c|c|}
\hline \multirow[t]{2}{*}{ No. } & \multicolumn{3}{|c|}{ Auc (1646.91-1662.34 cm-1) } \\
\hline & Day-1 & Day-2 & Day-3 \\
\hline 1 & 0.0440 & 0.0428 & 0.0435 \\
\hline 2 & 0.0431 & 0.0431 & 0.0430 \\
\hline 3 & 0.0424 & 0.0439 & 0.0432 \\
\hline 4 & 0.0420 & 0.0422 & 0.0442 \\
\hline 5 & 0.0432 & 0.0427 & 0.0435 \\
\hline 6 & 0.0424 & 0.0420 & 0.0423 \\
\hline Average & 0.0429 & 0.0428 & 0.0433 \\
\hline Deviation standard & 0.0007 & 0.0007 & 0.0006 \\
\hline$\%$ Rds & 1.7262 & 1.6177 & 1.4797 \\
\hline \% Recovery & 99.26 & 99.09 & 100.22 \\
\hline
\end{tabular}

Auc: area under the curve, RDS: relative deviation standard

Table 6: Intra-day precision data of vitamin B6 standard

\begin{tabular}{|c|c|c|c|}
\hline \multirow[t]{2}{*}{ No. } & \multicolumn{3}{|c|}{ Auc (1280.5-1315.21 $\left.\mathrm{cm}^{-1}\right)$} \\
\hline & Day-1 & Day-2 & Day-3 \\
\hline 1 & 0.2086 & 0.2029 & 0.2025 \\
\hline 2 & 0.2063 & 0.2055 & 0.1959 \\
\hline 3 & 0.2044 & 0.1980 & 0.1999 \\
\hline 4 & 0.2059 & 0.2077 & 0.2054 \\
\hline 5 & 0.2112 & 0.2027 & 0.2043 \\
\hline 6 & 0.2043 & 0.2031 & 0.1990 \\
\hline Average & 0.2068 & 0.2033 & 0.2012 \\
\hline Deviation standard & 0.0027 & 0.0032 & 0.0036 \\
\hline$\%$ Rds & 1.2947 & 1.5950 & 1.7767 \\
\hline \% Recovery & 99.26 & 100.00 & 98.95 \\
\hline
\end{tabular}

AUC area under the curve, Rds: relative deviation standard 
Based on these data, the relative standard deviation for vitamin B1 intra-day precision was $1.73 \%, 1.62 \%, 1.48 \%$, respectively, on the first, second, and third day. As for vitamin B6 gained by $1.29 \%$ on the 1 st; $1.60 \%$ on the 2 nd; then $1.78 \%$ on the 3rd day. Results obtained from the precision test of both active substances met the acceptance criteria relative standard deviation of $<2 \%$.

\section{Intermediate precision (inter-day precision)}

Intermediate precision will show the repeatability of response generated when the conditions of testing are variated; for example, it performs in different days, with variated analysts, equipment, and so forth [2-4]. In this experiment, precision testing was conducted for three days. Every day the sample was measured six times, with results shown in table 7

\section{Limit of detection (LOD) and limit of quantitation (LOQ)}

The limit of detection is the smallest amount of analyte in a sample that can still be detected but does not need its value can be known with certainty. Limit of quantitation is the smallest amount of analyte in a sample that can still be measured quantitatively [2-4]. The calculation used to determine the limit of detection, and limit of quantitation are based from the linearity equation/correlation curve. For vitamin B1 obtained: LOD $=0.079 \% \mathrm{w} / \mathrm{w}(0.00079 \mathrm{mg} / 100 \mathrm{mg})$ and LOQ $=0.2633 \% \mathrm{w} / \mathrm{w}(0.00263 \mathrm{mg} / 100 \mathrm{mg})$. Meanwhile for vitamin B6, the LOD was $0.093 \% \mathrm{w} / \mathrm{w}(0.00093 \mathrm{mg} / 100 \mathrm{mg})$ and the $\mathrm{LOQ}=0.311 \% \mathrm{w} / \mathrm{w}(0.00311 \mathrm{mg} / 100 \mathrm{mg})$. All of $(\mathrm{mg} / \mathrm{mg})$ describe the portions of drug substances in kbr dispersion plat.

\section{Range}

The range is the interval between the lower and upper limit of analyte concentration, which still can be measured quantitatively. This parameter must be proven and supported by the results of precision, accuracy, and linearity [2-4]. The calibration curve yielded shows that the concentration range of each substance was equal to 0.5 to $3.00 \% \mathrm{w} / \mathrm{w}$.

Finally; all the results from the validation of methods have been proven qualified acceptance. Therefore, the assay can be used for vitamins B1 and B6 determination simultaneously on the sample multivitamin tablets.

Table 7: Inter-day precision data of vitamin B1 and B6 standards

\begin{tabular}{lll}
\hline Day & Auc (at 1646.91-1662.34 $\left.\mathbf{~ c m}^{-1}\right) / \mathbf{B 1}$ & Auc (at 1280.5-1315.21 $\left.\mathbf{~ m}^{-1}\right) / \mathbf{B 6}$ \\
\hline 1st & $0.0429 \pm 0.0007$ & $0.2068 \pm 0.0027$ \\
2nd & $0.0428 \pm 0.0007$ & $0.2033 \pm 0.0032$ \\
3th & $0.0433 \pm 0.0006$ & $0.2012 \pm 0.0036$ \\
Average & 0.0430 & 0.2037 \\
Deviation standard & 0.0003 & 0.0028 \\
\% RDS & 0.5824 & 1.3910 \\
\hline
\end{tabular}

Auc: area under the curve, Rds: relative deviation standard, Based on these data, the relative standard deviation of the inter-day precision was $0.58 \%$ for vitamin B1 and $1.39 \%$ for vitamin B6. The results meet the acceptance criteria of value stated as $<2 \%$.

\section{Determination of levels of multivitamin tablet}

The assay method has been validated; then it was expected can be used to analyze two kinds of multivitamin tablets from the market, generic and branded name. Firstly, twenty tablets of each product were taken, next weighed and crushed homogeneous. Furthermore, a number of sampled of vitamin B1 and B6 equivalent of 100 and $200 \mathrm{mg}(100 \%$ concentration) were picked out then mixed and pressed with $\mathrm{KBr}$, following measurement using FTIR. Table 8 shows the levels on vitamin B1 in tablet samples.

Table 8. Level of vitamin B1 in multivitamin tablets (dose: $100 \mathrm{mg}$ )

\begin{tabular}{lllll}
\hline Tablet & Average of weight per tablet (mg) & $\begin{array}{l}\text { Average of AUC } \\
\text { (at 1646.910-1662.34 } \mathbf{~ m}^{-\mathbf{1}} \text { ) }\end{array}$ & Drug content per tablet (mg) & Level of drug in tablet (\%) \\
\hline A & $601.23 \pm 4.94$ & $0.0443 \pm 0.0008$ & 102.05 & 102.05 \\
B & $532.13 \pm 7.75$ & $0.0466 \pm 0.0040$ & 105.67 & 105.67 \\
\hline
\end{tabular}

$\mathrm{n}=20$, A: generic tablet, B: branded name tablet, Auc: area under the curve, Meanwhile table 9 shows the level of vitamin B6 in the sample of multivitamin tablets.

Table 9: Level of vitamin B6 in multivitamin tablets (dose: $200 \mathrm{mg}$ )

\begin{tabular}{lllll}
\hline Tablet & $\begin{array}{l}\text { Average of weight per tablet (mg) } \\
\mathbf{n = 2 0}\end{array}$ & $\begin{array}{l}\text { Average of auc } \\
\text { (at 1280.5-1315.21 } \mathbf{~ m}^{-1} \mathbf{)}\end{array}$ & Drug content per tablet (mg) & Level drug in tablet (\%) \\
\hline A & $601.23 \pm 4.94$ & $0.2015 \pm 0.023$ & 198.61 & 99.30 \\
B & $532.13 \pm 7.75$ & $0.2066 \pm 0.010$ & 203.45 & 101.72 \\
\hline
\end{tabular}

$\mathrm{n}=20$, A: generic tablet, B: branded name tablet, Auc: area under the curve

From these test results, it can be concluded that both the tablet product has met the criteria required by the Indonesian Pharmacopoeia V for vitamin B1 and B6 at $90-110 \%$ and $95-115 \%$ respectively [1].

So far, FTIR is still not commonly used for quantitative analysis because of its lack specificity. However, some experiment has been reported $[17-20]$. In this research, the sensitivity was increased by change absorbance spectrum into derivate value. The results which shown in fig 3, 4 and 5, 6 describes that this technique was adequate. As known, derivatization will sharpen curves, which can separate the extremity point clearly. This method also commonly has been used in ultra violet spectrophotometry to analyze compound mixtures [21-23]. In some previous research, the derivatization was not be done, because, in some cases, the specific spectra could appear clearly $[17,19]$.

From a wave number, scanning of 500-3500 $\mathrm{cm}^{-1}$, the derivate absorbance spectrum of vitamin B1 at the wave number 1800-1100 $\mathrm{cm}^{-1}$ shows some sharp spectrums (fig. 1). However, not of all has a consistent data after plotted to its area under the curve. From at least five spectra, it has been found the finest at two areas: 1662.34$1700.91 \mathrm{~cm}^{-1}$ and $1646.91-1662.34 \mathrm{~cm}^{-1}$ (fig. 2). Then these spectral were chosen as the candidates. After composed the regression 
curves, the best linearity was shown by the second spectra (table 1 , fig. 3 and 8). Fig. 3 shows the derivated absorbance spectra, mean while fig. 8 is the regression curve. Therefore, this spectrum was next fixed to be a base for quantitative measurement. That is- $\mathrm{NH}$ primer vibration, which has the most specific and strong vibration energy site $[15,16]$. This functional group position is described in the molecule structure in fig. 10 as follows:

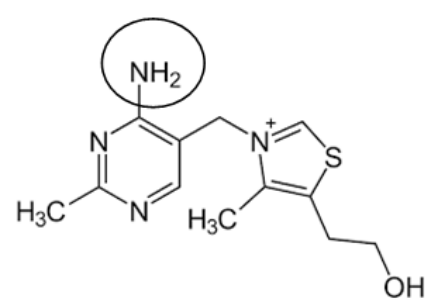

Fig. 10: The primer-NH of vitamin B1 molecule (circle signed) [5]

As same as vitamin B1, B6 also has some strong peaks in 1800-1100 $\mathrm{cm}^{-1}$ (fig. 4). After the next screening had performed, two candidates were found for the base of quantitative analysis. These spectrums were 1531.2-1569.77 $\mathrm{cm}^{-1}$ and 1280.5-1315.21 $\mathrm{cm}^{-1}$ (table 2). However, the finest linearity parameter was shown by the second area peak (table 2, fig. 6 and 9). Fig. 6 shows the derivated absorbance spectra in this area, meanwhile fig. 9 is its regression curve. The spectra represent C-O phenolic of vitamin B6 (fig. 11), which finally was fixed to be used for quantification measurement. From the experimental data shown, the screening of the best spectrum, transformation to absorbance function, derivatization, measurement of area under the curve, and composing a regression curve are the principal steps of quantitative FTIR method.

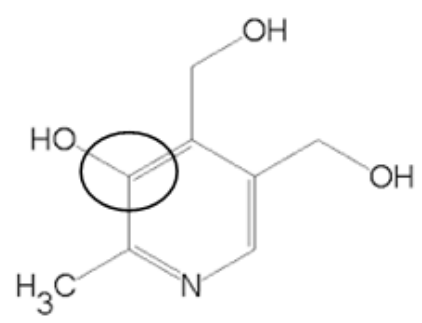

Fig. 11: The C-O bond of vitamin B6 molecule (circle signed) [6]

The other validation parameters should be tested after found the specific and consistent spectra. Firstly, the LOD and LOQ were determined based on the regression curve equation (fig. 8 for vitamin B1 and fig. 9 for B6) [2-4]. Using equation LOD and LOQ of vitamin $B 1$ was found $=0.00079 \mathrm{mg}$ and $0.00263 \mathrm{mg}$ per $100 \mathrm{mg}$ $\mathrm{kbr}$, meanwhile vitamin B6 was $0.00093 \mathrm{mg}$ and $0.00311 \mathrm{mg}$ per $100 \mathrm{mg}$ solid dispersion, respectively.

The next validation parameters were accuracy and precision evaluation, which all of the tests yielded the met results with the requirement criterions. The data are shown in table 3 and 4 for vitamin B1 and B6 accuracy test. Meanwhile, table 5 and 6 are the results of intra-day precision, and table 7 is the inter-day data test of both vitamins. These results more convincing that FTIR is adequate for analyze this vitamin combination.

Next, range observation test showed that the amount of vitamins B1 and B6 can be measured by FTIR were $0.005-0.03 \mathrm{mg}$ sample in 100 $\mathrm{mg} \mathrm{kbr}$ crystal as the dispersant. It means that small enough sample needed to be measured. As the comparison, there has been some analysis of B1 and B6 mixture, which used HPLC method with some detector types. In the example, the range concentration determined by HPLC-UV detector was $\pm 500-1500 \mu \mathrm{g} / \mathrm{ml}$ or about $0.5-1.5$ $\mathrm{mg} / 100 \mathrm{ml}$ in the solution [13]. The other research used HPLC-dad and reported that LOD of B1 and B6 were 16.5 and $6.3 \mu \mathrm{g} / \mathrm{l}$, mean while the LOQ-s were 50.0 and $19.0 \mu \mathrm{g} / \mathrm{l}$ [14].

If assumed that $1 \mathrm{mg}$ solid dispersion is equal with $1 \mathrm{ml}$ solution, this developed method shows higher sensitivity and selectivity compared to HPLC-UV detector [13]. Next, this method has the sensitivity which almost similar with HPLC-DAD [14]. Moreover, the FTIR direct method offers some advantages such as the simpler preparation, needs no solvents, and totally less costly. The tablet samples just prepared by crushed, mixed and ground with the potassium bromide crystal, afterward compressed to be a plate then measured directly.

Finally, this validated method tried to be used for determining the content of tablet dosage forms. There were two kinds tablets tested, one was a generic tablet, and the other was a branded name. The assay performed yielded a good result as shown in table 10 and 11 . Both vitamins can be determined in all tablets simultaneously, which proven fulfill the content range required in the compendia [1]. This data described that the method is useful for determining vitamins $\mathrm{B} 1$ and $\mathrm{B} 6$ in their combination dosage forms.

Actually, this research needed more products to be tested, but unfortunately, so far only this two kind of tablets, which can be found in the market. This considered that in many communities, still there is an opinion that the generic products have inadequate quality $[9,10]$. The other reason in these chosen samples is, that each formula uses the almost totally different excipient or tablet matrix, which will effect on the assay. However, the results of content determination of both kind tablets showed the statistically insignificant values, after checked with ANOVA with $p<0.05$ [21]. This data is in line with the expectation about the generic-drug quality, which has been concerned by WHO [10]. Moreover, it should be suggested to evaluate some more tablet products, then can draw the more objective and undoubtedly opinions about the unbrandedname products.

\section{CONCLUSION}

FTIR can be used for the assay of vitamins B1 and B6 simultaneously at specific wavelengths $1646.91-1662.34 \mathrm{~cm}^{-1}$ for B1 and 1280.5$1315.21 \mathrm{~cm}^{-1}$ for B6. This method has met the validation criteria, includes specificity, linearity, accuracy, precision intra-day, inter-day precision, detection limit, quantitation limit, and range. The range is $0.005-0.03 \mathrm{mg}$ vitamins mixture in $100 \mathrm{mg}$ mixture with $\mathrm{kbr}$. This method has been successfully tried to determine the content of two combination tablet products from the market. The results showed that the tablet samples has been met compendia requirements.

\section{Suggestion}

As an alternative method, next this method should be performed simultaneously with the compendia method using the same samples.

\section{CONFLICT OF INTERESTS}

Declared none

\section{REFERENCES}

1. Ditjen POM, Kemenkes RI. Farmakope Indonesia. ed. V Jakarta: Kemenkes RI; 2014. p. 1025-6, 1265-7.

2. Incledon C, Lam H. Development and validation of automated methods. In: Chan CC, Lam H, Lee YC, Zhang XM. eds. Analytical method validation and instrument performance verification. New Jersey: John Wiley and Sons; 2004. p. 75-9.

3. International Conference of Harmonization. Q2 Validation of Analytical Procedures: Text and methodology international conference on harmonization of technical requirements for registration of pharmaceutical for human use. Canada: ICH Harmonized Tripartite Guideline; 2005.

4. Harmita. Petunjuk pelaksanaan validasi metode dan cara perhitungannya. Majalah Ilmu Kefarmasian 2004;1:117-35.

5. Al-Rashood KAM, Thiamine hydrochloride. In: Florey K, Brewer GA, Papariello LC, Comer JP, Olin SM, Senkowski B. eds. Analytical profiles drug substances. New York: Academic Press; 1986. p. 418. 
6. Enein HYA, Loutfy MA. Pyridoxine hydrochloride. In: Florey K, Brewer GA, Papariello LC, Comer JP, Olin SM, Senkowski B, eds. Analytical profiles of drug substances. Academic Press: New York: Academic Press; 1986. p. 452.

7. Ikatan Apoteker Indonesia. Informasi Spesialite Obat Indonesia. Vol. 50th. Jakarta: Ikatan Apoteker Indonesia; 2016.

8. Medidata. The Monthly Index of Medical Specialities Indonesia. Vol. 16th. Jakarta: Buana Ilmu Populer; 2016.

9. Buhler V. Generic Drug Formulations. $2^{\text {nd }}$ ed. Ludwigshafen: BASF Fine Chemicals; 1998.

10. Robert G Bell. Improving the quality of generic drugs. White paper. University Research Co Ltd; 2015. p. 1-20.

11. United States Pharmacopoeia Conv. USP 38/NF 33. Washington DC: US Pharmacopeia; 2015.

12. The British Pharmacopoeia Commission. British Pharmacopoeia 2013. London: British Pharmacopoeia Commission; 2013.

13. Sánchez-Machado DI, López-Cervantes J, López-Hernández J, Paseiro-Losada P. Simultaneous determination of thiamine and riboflavin in edible marine seaweeds by high-performance liquid chromatography. J Chrom Sci 2004;42:117-20.

14. Antakli S, Sarkees N, Sarraf T. Determination of water-soluble vitamins b1, b2, b3, b6, b9, b12 and c on c18 column with particle size $3 \mu \mathrm{m}$ in some manufactured food products by HPLC with UVdad/fld detection. Int J Pharm Pharm Sci 2015;7:219-24.

15. Skoog DA, Crouch SR, FJ Holler. Principles of instrumental analysis 6th edn. Belmont: Thomson Higher Education; 2007. p. 430-80.

16. Furniss BS, Hannaford AI, Smith PWG, Tatchell AR. Vogel's textbook of practical organic chemistry. $5^{\text {th }}$ edn. New York: John Wiley and Sons; 1989. p. 275-93.
17. Rakesh $\mathrm{P}$, Charmi $\mathrm{P}$, Rajesh. Quantitative analytical applications of FTIR spectroscopy in pharmaceutical applied areas. J Adv Pharm Educ Res 2014;4:145-57.

18. Bhongade B, Talath $S$, Dhaneswar S. A validated method for the quantitation of ciprofloxacin hydrochloride using diffuse reflectance infrared Fourier transform spectroscopy. Int J Spectrosc 2014:1-4. http://dx.doi.org/10.1155/2014/294612

19. Pandey S, Pandey P, Tiwari G, Tiwari R, Rai AK. FTIR spectroscopy: a tool for quantitative analysis of ciprofloxacin in tablets. Indian J Pharm Sci 2012;74:86-90.

20. Nugrahani I, Musaddah M. Development and validation analysis of acyclovir tablet content determination method using FTIR. Int J Appl Pharm 2016;8:43-7.

21. Kus S, Marczenko Z, Obarski N. Derivative uv-vis spectrophotometry in analytical chemistry. Chem Anal 1996;41:899-927.

22. Tabbouche OS, Soukkariyyeh I. First-order derivative ultraviolet spectrophotometry of imipenem cilastatin formulations. J Taibah University Sci 2014;9:178-81.

23. Patel PA, Dole MN, Shedpure PS, Sawant SD. Spectrophotometric simultaneous estimation of salbutamol and ambroxol in bulk and formulation. Asian J Pharm Clin Res 2011;4:42-5.

24. SPSS. Principles of research design. UK: SPSS Ltd; 2000. p. 302-30.

\section{How to cite this article}

- Ilma Nugrahani, Citra Kartini. Determination of thiamine HCL (Vitamin B1) and pyridoxine HCL (VITAMIN B6) Content in tablet by FTIR. Int J Pharm Pharm Sci 2016;8(10):257-264. 